\title{
Simone Vermeeren
}

\section{Isabella}

\section{De circulariteit in het werk van de prerafaëlieten}

In de National Gallery in Londen was tot 2 april 2018 de tentoonstelling 'Reflections: Van Eyck and the Pre-Raphaelites' te zien. Centraal stonden twee kunststromingen die van elkaar worden gescheiden door vijf eeuwen, en toch vele gelijkenissen met elkaar vertonen. De negentiende-eeuwse prerafaëlieten lieten zich inspireren door de Vlaamse primitieven. In hun werk waren oude tradities niet ondergeschikt aan nieuwe technieken, en met die visie keerden de prerafaëlieten zich tegen het vooruitgangsdenken van hun tijd. Dit artikel verkent hoe kunst veranderende opvattingen van tijd en geschiedenis letterlijk visualiseert.

De oude en oververhitte beamer zorgde ervoor dat de projectie van het schilderij Isabella van prerafaëliet John Everett Millais op de muur voor me lichtjes bewoog. In een hoorcollege Moderne Kunstgeschiedenis stopte ik even met meeschrijven met de docent om het gedetailleerde schilderij goed op me in te laten werken. Bijna terloops maakte de docent, die net was begonnen aan een verhandeling over de kritiek die Millais (1829-1896) in de eerste jaren van zijn carrière voor de kiezen kreeg, een opmerking die ik nooit meer vergeten ben: 'Dat perspectief klopt natuurlijk niet. Kijk maar eens. Er zitten veel te veel mensen aan die tafel.'

Mijn aandacht werd in eerste instantie getrokken door het tafereel op de voorgrond van het schilderij. Daar is het gespierde, in een maillot gehulde, bovenbeen van een jongeman te zien, en een hond die zijn kop laat rusten op de schoot van een dame met een kunstig kapsel, terwijl het dier de toeschouwer alert in de gaten lijkt te houden. Pas na de opmerking van de docent zag ik dat er inderdaad maar liefst acht mensen naast elkaar op dat rijkversierde bankje aan de rechterkant zitten. Een bankje dat in 
werkelijkheid hoogstens drie mensen zou kunnen dragen - zie het gezelschap aan de andere zijde van de tafel - is door Millais uitgerekt tot onwerkelijke proporties (zie afbeelding 1). Ik keek naar het schilderij, en bleef kijken, ondanks de slechte kwaliteit van de projectie. Terwijl ik keek, begonnen in mijn gedachten losse draadjes zich met elkaar te verbinden; ik begon een groter geheel te zien. Dat vreemde perspectief veranderde mijn complete kijk op de geschiedenis.

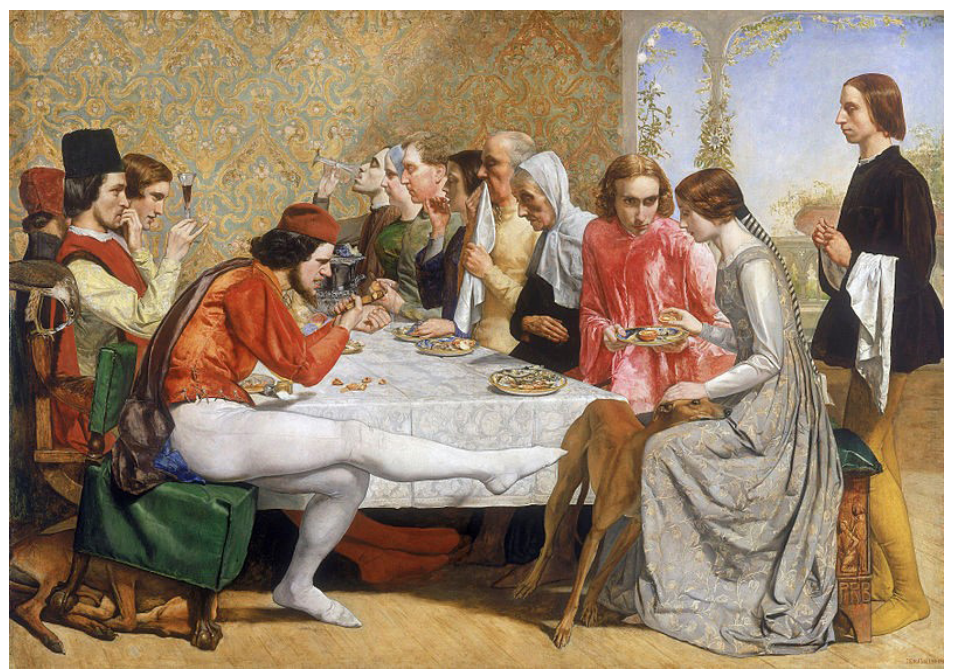

Afbeelding 1. Lorenzo and Isabella door John Everett Millais (1849). Olieverf op doek. Afmetingen: 103 x $142.8 \mathrm{~cm}$. Signatuur: "JE Millais 1849 PRB". Walker Art Gallery, Liverpool.

\section{Een Londens broederschap}

Tussen al het olieverfschoon dat de schilderkunst in de tweede helft van de negentiende eeuw heeft voortgebracht, zijn de prerafaëlieten behoorlijk ondergesneeuwd. Wie aan die periode denkt, schiet immers als eerst het realisme van Courbert, Millet en Manet, de romantiek van Turner of juist het impressionisme van Monet te binnen. De prerafaëlieten of de Pre-Raphaelite Brotherhood zoals zij zichzelf noemden (zie de gegraveerde PRB op het bankje aan de rechterzijde van afbeelding 1), waren talrijk noch geografisch verspreid. De groep modernistische kunstenaars hield zich namelijk vrijwel alleen op in Londen. Millais was samen met William Holman Hunt (1827- 
1910) en Dante Gabriel Rossetti (1828-1882) een van de stichters van de kunstbeweging, in het revolutiejaar 1848. Ze waren alle drie recalcitrante studenten aan de Royal Academy of Arts en het in alles hartgrondig oneens met hun docenten. ${ }^{1}$ Later voegden zich nog eens vier andere kunstenaars bij de broederschap - kunstenaars, want deze mannen beperkten zich niet tot de schilderkunst. Het gezelschap bestond uit schilders, dichters, kunstcritici en een beeldhouwer. De kunstgeschiedenisboeken leren ons dat het gezelschap, hoewel het maar kort bestond en weinig talrijk was, wel zo invloedrijk was dat het aan de wieg stond van de Duitse Jugendstil. ${ }^{2}$

In een periode die werd gekenmerkt door realisten zetten, de prerafaëlieten zich juist af tegen de opvatting die halverwege de negentiende eeuw dominant was: namelijk dat het de taak van een schilder was om levensechte afbeeldingen te maken. 'Levensecht' had vanuit dit standpunt twee definities. De eerste betrof de techniek waarbij schilderijen een op een kopieën moesten zijn van de werkelijkheid. Perspectief en verhoudingen moesten werkelijk perfect uitgevoerd worden. Onder deze druk bezocht Rosa Bonheur (1822-1899), de meest gevierde vrouwelijke schilder van de negentiende eeuw, slachthuizen om daar urenlang de karkassen van dode paarden te bestuderen, voordat zij zelfs maar begon aan het schetsen van deze dieren. ${ }^{3}$ Het andere keurslijf waarin de negentiende-eeuwse kunstopvatting de schilders dwong, was de thematiek. De historiestukken, afbeeldingen van bijbelse en mythologische scènes zoals de opstand van Julius Civilis, waar Rembrandt zijn hedendaagse roem aan te danken heeft, waren in deze periode namelijk uit de mode, net als de portretten van de aristocratie. Realisten spoedden zich en masse naar het platteland en schilderden hardwerkende zaaiers of begaven zich onder de arbeidersklasse, om zoals Rémy Cogghe (1854-1935) een hanengevecht vast te leggen. In de tweede helft van de negentiende eeuw stond 'het echte leven' centraal in de schilderkunst. ${ }^{4}$

Alle studie die vooraf ging aan de creatie van realistische kunstwerken, door hen 'academisch' genoemd, stond Hunt, Rossetti en Millais tegen. Zelf waren ze een groot voorstander van een natuurgetrouwe werkwijze, waarin 'natuurgetrouw' letterlijk werd opgevat: met veel aandacht voor kleine details en voor de organische vormen uit de natuur. Het Realisme is op het eerste oog misschien wel natuurgetrouw, maar Millais en consorten zagen deze stroming vooral als een overgestileerd en statische benadering van de schilderkunst - zonder ruimte voor spontaniteit, fantasie of gevoel; alle 
modellen en onderwerpen werden eindeloos bestudeerd en geënsceneerd. Kortom: weinig spontaan, en met weinig ruimte voor gevoelens of emoties. ${ }^{5}$ De verheerlijking van renaissancistische schilderkunst aan de Academy of Arts, een stroming die naast vele andere kenmerken toch vooral wordt geroemd om de ontdekking van het perspectief, beviel hen evenmin. Ze haalden hun inspiratie liever uit de periode van voor de Renaissance, en van vóór Rafaël Santi. ${ }^{6}$ De prerafaëlieten lieten, net als de middeleeuwse Vlaamse primitieven, de actie op hun schilderijen bij voorkeur op de voorgrond afspelen. Die imitatie van de primitieven verklaart de vertekening van het perspectief, die Millias bewust aanbracht in het schilderij Isabella (zie afbeelding 2). De vaak wat doffe en in elkaar overvloeiende kleuren van de realisten vindt men ook niet op prerafaëlitische paletten; ze kozen voor harde tinten en contrasterende composities, dat goed terug te zien is op Esthervan Millais (zie afbeelding $2)^{7}$

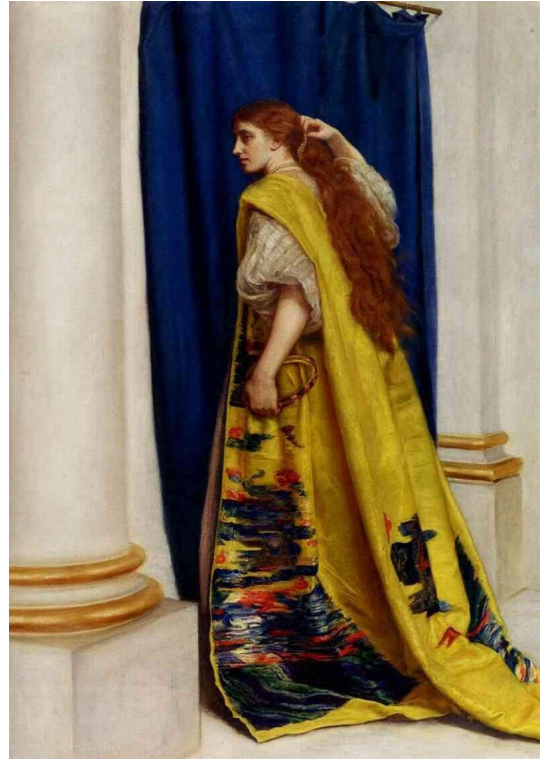

Afbeelding 2. Esther door John Everett Millais (1865). Olieverf op doek. Afmetingen: $77.4 \times 106 \mathrm{~cm}$. Privécollectie.

\section{Isabella en de pot met basilicum}

De onachtzaamheid voor perspectief is een kenmerk voor de prerafaëlieten. Een ander is de stap die zij qua thematiek terug in tijd zetten. Zij kozen niet voor alledaagse taferelen, met hardwerkende boerengezinnen of verlaten landweggetjes, maar combineerden literaire ontwikkeling met fantasie en creëerden historiestukken, bijbelse taferelen en gaven literaire personages een gezicht. Dante Rossetti schilderde de engelachtige Beatrice uit De Goddelijke Komedie van zijn naamgenoot en op misschien wel zijn bekendste schilderij verbeelde Millais Shakespeares Ophelia. ${ }^{8}$ Isabella is een afbeelding van een scène uit het gedicht van de Engelse dichter John Keats. Keats behoorde tot dezelfde generatie Romantici als Lord Byron en Percy 
Shelley en haalde, net als de prerafaëlieten, zijn inspiratie uit mythes en Middeleeuwse geschriften. ${ }^{9}$

Isabella, or The Pot of Basil vertelt een passage uit Boccaccias Decamarone na, het verhaal van twee gedoemde geliefden, Isabella en Lorenzo. Isabella, de jonge vrouw die op het schilderij en profil op het rechterbankje te zien is, is afkomstig uit een adellijke familie. Haar aanbidder, die op het schilderij naast haar zit, is dat niet. De twee broers van Isabella, beide afgebeeld aan de linkerzijde van het schilderij, willen een, vooral voor henzelf gunstige, huwelijksovereenkomst sluiten voor hun zus. Wanneer ze lucht krijgen van de romance tussen de twee jongelingen, bereiden ze een moord op Lorenzo voor. Inderdaad wordt Lorenzo niet veel later in een bos om het leven gebracht en Isabella, die denkt dat hij haar heeft verlaten, is radeloos. Pas als ze over hem droomt, komt ze achter de ware toedracht van zijn verdwijning en haast ze zich naar het bos om daar haar geliefde op te graven. In het lugubere slot van het gedicht snijdt ze het hoofd van Lorenzo af, neemt het mee naar huis en verstopt het in een bloempot, die ze bewatert met haar eigen tranen en waaruit een grote bos basilicum groeit. ${ }^{10}$

Het lot van de twee jonge geliefden wordt op het schilderij van Millais al aangekondigd, als je eenmaal weet waar je op moet letten. Het diner en de lange tafel dienen als motief om alle personages uit het gedicht bij elkaar te brengen, we zien het moment waarop bij de beide broers het besef ontstaat dat hun zuster door Lorenzo wordt verleid. De ene broer houdt het glas wijn alleen als voorwendsel voor zijn gezicht: het geeft hem een excuus om zijn zuster en haar geliefde te bestuderen en zich te verbijten. De andere broer, uiterst rechts gezeten op het linkerbankje, kan zijn emoties minder goed in bedwang houden; hij schopt naar een hond, kraakt agressief een noot de kruimels liggen overal op tafel - en balanceert onmachtig op zijn stoel. Isabella en Lorenzo hebben ondertussen alleen maar oog voor elkaar.

De prerafaëlieten schilderden het liefst menselijke, mythische taferelen, met veel ingehouden drama en symboliek en met verheven afbeeldingen van personen. Daarbij valt opnieuw op hoeveel afstand ze deden van de realistische stijl van andere schilders. Prerafaëlietische figuren lijken niet op doodgewone, dagelijkse figuren. Ze zijn statig, hebben verheven gezichtstrekken en aristocratische ledematen - al helemaal in vergelijking met de ploeterende steenbrekers van Courbet. Historicus Simon Schama, die onder andere is gespecialiseerd in kunstgeschiedenis, omschrijft de 
late prerafaëlieten, en dan met name de portretten die Rossetti schilderde van zijn minnaressen, als Victoriaanse soft porn, vanwege de dramatische thema's, weelderige haardossen en smachtende poses. ${ }^{11}$ Het dramatische en sentimentele dat van prerafaëlitische schilderijen afspat en dat Schama wel waardeert, werd destijds niet met open armen ontvangen. ${ }^{12}$ Charles Dickens bezocht de eerste tentoonstelling van het broederschap, waar onder andere Millais' Christ in the House of His Parents te zien was. ${ }^{13}$ Op het schilderij zijn Jezus, Jozef en Maria afgebeeld als eenvoudige arbeiders die hard werken in de timmerwerkplaats van Jozef. De vloer is niet aangeveegd, overal ligt modder en de figuren zien er oud en uitgeput uit. Dit alles beviel Dickens niet: hij zag in de Heilige Maagd een alcoholiste, vond het ontluisterend om het gezin op deze alledaagse manier afgebeeld te zien. ${ }^{14}$ Hoewel de prerafaëlieten, naarmate ze langer bestonden steeds meer op waardering konden rekenen en Millais later in zijn carrière bewonderd werd, was Dickens in de beginjaren niet de enige die kritiek had op de vernieuwde werkwijze van de broederschap.

Tegenwoordig is die waardering voor de prerafaëlieten geïnstitutionaliseerd, hoewel ze nog altijd geen erg populaire of bekende stroming zijn onder (kunst-)historici. Vermoedelijk komt dat omdat ze maar kort bestonden en maar met weinigen waren. Tussen 2 oktober 2017 en 2 april 2018 was in de National Gallery in Londen een expositie te zien met de naam 'Van Eyk and the Raphaelites', het Walker Museum in Liverpool heeft vele prerafaëlitische schatten in de permanente collectie. In de Londense tentoonstelling worden schilderijen van Millais, Rosetti, Hunt en hun broederschapsgenoten geëxposeerd naast de laatmiddeleeuwse Vlaamse Primitieven om een op een te demonstreren waar de prerafaëlieten hun inspiratie vandaan haalden. Overeenkomsten tussen beide stijlen die onmiddellijk in het oog springen, zijn het placeren van de actie, of het belangrijkste element uit het schilderij, op de voorgrond en het gelijksoortig gebruik van perspectief.

\section{Circulair}

Toen ik Isabella voor het eerst zag, was ik een negentienjarige student geschiedenis. Hoewel ik kon buigen op een behoorlijke feitenkennis, had ik nog geen inzicht in een groter geheel; ik kon het verleden niet overzien. Het geschiedenisonderwijs in Nederland, dat voor de meeste scholieren niet eens een verplicht onderdeel is, is vormgegeven vanuit een sterk idee van vooruitgang: duizenden jaren geleden waren mensen nog jagers en 
verzamelaars, maar de uitvinding van het vuur, het wiel, de stoommachine, de trias politica, de overwinning op het nazisme en de pokken hebben ervoor gezorgd dat er geen betere tijd is om in te leven dan het heden. Dat lineaire narratief was mijn enige voorbereiding op wetenschappelijk onderwijs en bij mijn aanvang op de universiteit had ik niet genoeg intellectuele bagage om daar enige nuance in aan te brengen.

Ook de schilderkunst had ik tot dan toe gezien als een lineair proces, waarin kunstenaars constant bezig waren hun techniek te verbeteren en zochten naar nieuwe manieren om hun boodschap over te brengen. Of zij impressionisten, kubisten of dadaïsten waren, dat deed er wat mij betreft niet toe omdat al deze stromingen in hun eigen tijd vernieuwend waren. Ik dacht dat kunst vernieuwend moest zijn, vernieuwing omwille van de vooruitgang. Waar ik nog nooit eerder bij had stilgestaan, was de mogelijkheid dat artiesten terug wilden in de tijd, dat zij verloren gewaande technieken en thema's weer naar boven wilden halen. Niet om ze te perfectioneren, maar om ze te eren.

De prerafaëlitische hang naar de middeleeuwen, zowel thematisch als technisch, was voor mij het eerste, min of meer tastbare, voorbeeld waaruit bleek dat de geschiedenis niet alleen bestaat uit een constant streven naar vooruitgang; dat het verleden er niet alleen is om de huidige tijd, ondanks zijn eigen gebreken, gunstig bij af te laten steken. Millais en zijn broederschap geloofden niet dat de realistische beweging de kunst ten goede kwam. Zij zagen die moderne vernieuwing niet als een verbetering, maar wilden juist een element uit het verleden herintroduceren. Terugblikken op het verleden is net zo'n wezenlijk element in een menselijk leven als uitkijken naar de toekomst.

Ik had met deze constatering natuurlijk niet het ei van Columbus uitgevonden. Later zou ik lezen dat zoiets een 'circulaire geschiedopvatting' heet en dat in de eenentwintigste eeuw geen enkele, zichzelf respecterende historicus daadwerkelijk gelooft in een lineair historisch narratief. Ieder tijdperk heeft zijn eigen culturele hoogtepunten, die in de eeuwen daarna ontdekt en herontdekt zijn. De Romantische beweging aan het einde van de achttiende eeuw verheerlijkte de Middeleeuwen al voor de prerafaëlieten dat deden; de lange negentiende eeuw bracht honderden amateurarcheologen voort uit een collectieve fascinatie voor farao's en Mesopotamië - en wat was de hele Renaissance nu eigenlijk anders dan een herbeleving van de klassieken? 


\section{Vermeeren}

Volledig begrip van het gegeven dat het verleden in ieder tijdperk opnieuw geëvalueerd wordt, is uiteindelijk de voorwaarde voor het succesvol kunnen afronden van de studie geschiedenis - feitenkennis alleen is nooit genoeg. Het is tevens het publieke geheim van het gilde der historici. Op het moment dat ik dat besefte, kwam ik namelijk terecht ik in een lange, circulaire traditie van historici die in de voorbijgegane eeuwen tot dezelfde conclusie zijn gekomen. Ieder in zijn eigen tijd en op zijn eigen manier.

\section{Noten}

1. Caroline Bugler, 'The Pre-Raphaelite Brotherhood' in: Reflections. Van Eyk and the Pre-Raphaelites (Londen: The National Gallery, 2017), 25-29.

2. Fred S. Kleiner, Gardner's Art through the Ages. The Western Perspective (Boston: Wadsworth, 2010), 641-642.

3. Ibidem.

4. Ibidem.

5. Kleiner, Gardner's Art through the Ages, 634.

6. Bugler, 'The Pre-Raphaelite Brotherhood,' 25-29.

7. John Everett Millais, Esther, 1865. Olieverf op doek, privécollectie.

8. John Everett Millais, Ophelia, 1852. Olieverf op doek, Tate Gallery, Londen.

9. Jeffrey N. Cox, Poetry and Politics in the Cockney School: Keats, Shelley, Hunt and Their Circle (Cambridge: Cambridge University Press, 2004).

10. John Keats, Lamia, Isabella, the Eve of St. Agnes and Other Poems, (1820)

11. Simon Schama, The Face of Britain: a History of the Nation Trough Its Portraits (Londen: Penguin Vinkings, 2015), 228-238.

12. Bugler, 'The Pre-Raphaelite Brotherhood,' 25-29.

13. John Everett Millais, Christ in the House of His Parents, 1850. Olieverf op doek, Tate Gallery, Londen.

14. Charles Dickens, 'Old Lamps for New Ones.', in: Household Words 12 (Londen, 1850), $12-14$. 